\title{
Turismo indígena como alternativa de valorização cultural
}

\author{
Indigenous Tourism as alternative cultural enhancement
}

Djanires Lageano Neto de Jesus

\begin{abstract}
RESUMO
O objetivo deste artigo é apresentar reflexão teórica a fim de estimular a produção do campo epistemológico que trata do tema relacionado ao segmento turismo indígena. A metodologia do trabalho foi baseada na associação direta entre pesquisa bibliográfica e documental. No que tange à pesquisa bibliográfica, foram efetuadas leituras vinculadas aos estudos do turismo, da geografia e da antropologia. Sobre o aspecto documental da análise foram consultados planos, programas e projetos vinculados aos órgãos públicos que fomentam e qualificam o turismo brasileiro. Os resultados da pesquisa indicam que o turismo indígena, como acontece em várias localidades no Brasil e em outros territórios estrangeiros, principalmente na América Central e do Sul, incluindo a Argentina, Chile, Equador, Colômbia, México, entre outros países, em maior ou menor grau de desenvolvimento, tem como uma de suas funções a de potencializar a cultura local contribuído para a valorização cultural dos territórios.
\end{abstract}

PALAVRAS-CHAVE: Turismo Indígena; Cultura, Tradição; Identidade; Alteridade.

\section{ABSTRACT}

The purpose of this paper is to present a theoretical reflection to stimulate the production of the epistemological field that deals with the issue related to the indigenous tourism sector. The methodology of this study was based on the direct association between documentary and bibliographical research. Regarding the literature, readings were made related to tourism, geography and anthropology studies. About the documentary aspect of the analysis were consulted plans, programs and projects related to public agencies that promote and qualify the Brazilian tourism. The survey results indicate that the indigenous tourism, such as what happens in many communities in Brazil and other foreign territories, particularly in Central America and South America, including Argentina, Chile, Ecuador, Colombia, Mexico, among other countries, greater or lesser degree of development, has as one of its functions to enhance the local culture contributed for the cultural enhancement of territories.

KEYWORDS: Indigenous Tourism; Culture; Tradition; Identity; Otherness. 


\section{Introdução}

Observando o campo epistemológico disponível, principalmente focando no turismo, na antropologia e na geografia, as definições encontradas para o turismo indígena, pouco se apresenta de forma que atenda as necessidades globais do segmento, e mais ainda, que priorize as ansiedades socioeconômicas e culturais das próprias comunidades indígenas envolvidas.

Várias definições nessa tentativa de avançar sobre o conjunto de elementos que compõe o turismo indígena em si o tratam como conceito advindo do turismo cultural; turismo étnico ou etnoturismo; turismo nativo; turismo comunitário ou de base comunitária; ecoturismo; entre outras formas de encontrar uma definição mais real do que se intenta com um segmento bastante específico e delicado.

O turismo indígena, como acontece em diversas localidades brasileiras e estrangeiras, quando bem planejado e organizado, tem como uma de suas funções a de potencializar a cultura local, principalmente no que diz respeito aos elementos ligados à dança, ao artesanato e à pintura, ao canto e à reza, à língua nativa, às bebidas e comidas típicas, à agricultura, entre outros elementos tradicionais. Além disso, possibilita novas formas de subsistência familiar tanto para a sociedade indígena como aqueles envolventes aos seus territórios (JESUS, 2012).

Para que um território indígena se constitua um atrativo turístico, é imprescindível pensar em questões voltadas para o conjunto de vivências e realidades de tal povo. Para se entenderem as relações socioculturais dos e nos territórios indígenas torna-se necessária à compreensão de um processo subjetivo de construção territorial que contemple o espaço de reprodução física, subsistência e sobrevivência.

Dimensionar e avaliar as interferências diretas que o turismo indígena pode provocar nesses núcleos tradicionais é uma questão basilar para a constituição de uma atividade que valorize o espaço utilizado como reprodução cultural. A atividade turística possibilita ações de planejamento em longo prazo, com propostas de capacidade de suporte, conservação e revitalização da cultura. Por outro lado, também potencializa o turismo de massa, com forte apelo para o lucro fácil, que visa a resultados imediatistas, principalmente quando o fenômeno do turismo é tratado como slogan e apresenta-se como "solução" para a geração de empregos, ignorando-se, todavia os investimentos necessários para sua sobrevivência e manutenção (JESUS, 2012).

Nesse sentido de discutir essa relação dialética que permeia um processo de produção comercial do turismo associada ao patrimônio cultural, tanto de natureza material como imaterial, o objetivo do presente artigo é apresentar uma reflexão teórica para estimular a produção do campo epistemológico que trata do tema relacionado ao segmento: turismo indígena.

A metodologia do trabalho foi baseada na associação direta entre pesquisa bibliográfica e documental. No que tange à pesquisa bibliográfica, foram efetuadas leituras vinculadas aos estudos do turismo, da geografia e 
da antropologia. Sobre o aspecto documental da análise foram consultados planos, programas e projetos vinculados aos órgãos públicos que fomentam e qualificam o turismo brasileiro.

\section{A dialética da tradicionalização}

Nos recentes processos de mudanças socioculturais e econômicas, a história assume papel fundamental enquanto fator explicativo de identidades locais particulares. Surgem, ainda, associadas a um movimento generalizado de reação aos efeitos da globalização, ações que estimulam a cada dia - a construção, produção e reprodução de recursos, além da redefinição dos espaços de uso comum, principalmente relacionados aos patrimônios e bens culturais.

A criação do patrimônio cultural baseia-se no aproveitamento de elementos das identidades, memórias locais e na sua recriação. É construída nova imagem, que se pretende apelativa e harmoniosa, para novas localidades turísticas. Esses fenômenos fígados as tradições ocorrem essencialmente no nível dos discursos produzidos sobre o passado das comunidades e das suas populações. Apesar de reconhecer que o elemento histórico sempre esteve presente nas identidades locais, atualmente, existe mudança do nível e das formas de como os discursos sobre esse assunto são proferidos. Um dos elementos que caracteriza essa transformação é a participação ativa dos poderes e forças políticas nos processos de construção de identidade.

A reconstrução do passado, motivada pelo processo de patrimonialização e desenvolvimento econômico, surge sob o impulso dos agentes políticos locais e esse fato conduz à consciência patrimonial diferente, associada à possibilidade de captar apoios financeiros para as localidades potenciais. Assim, além das próprias populações e comunidades tradicionais, intervêm, ainda, no processo de construção patrimonial, entre outros, os representantes do poder político nacional, estadual e municipal; os mediadores que estabelecem conexão entre as várias instâncias de decisão e distribuição de recursos financeiros existentes e, ainda, os investidores da iniciativa privada, que encontram, nesses projetos, mercado de trabalho em expansão e formas de legitimação profissional (JESUS, 2012).

Nesse contexto, Silvano (2002) indica que a cultura popular está cada vez mais materializada, objetificada e mercantilizada e, sob este processo, provoca a transformação de determinados traços da vida tradicional em objetos representativos da cultura nacional, regional e local. Isso, muitas vezes, associa-se a ideia de se falar em cultura como própria, específica e autêntica. Vários eventos são utilizados como objetificação cultural, como os rituais religiosos, as festas profanas, a demonstração do artesanato, a dança e a comida típica. Tais vivências, diante da globalização de mercado, tornam-se valor de troca, de consumo e estabelecem relação comercial de bens e serviços.

A representação provocada entre os elementos que compõem o contexto cultural serve de base para compreender as diferenciações e 
interpretações sobre as comunidades ditas "tradicionais". Nesse caso, citam-se as comunidades indígenas, diante do atual sistema econômico moderno, onde a premissa do acúmulo de capital é fator preponderante de sobrevivência, em seus processos de adaptações severas sobre os valores socioculturais tradicionais.

Nesse sentido, Löwen Sahr (2008, p. 224) defende que:

[...] povos e comunidades tradicionais, só podem ser tidas como tradicionais quando vistas num contexto dinâmico mais amplo, o da sociedade moderna. Suas diferenciações, entretanto, não devem significar o aprisionamento das mesmas a uma única racionalidade, seja ela tradicional ou moderna. (...) Assim, se para a manutenção e recriação dessas comunidades existe a tendência de reprodução de seu sistema autossustentável e singular, existe também uma tendência modernizadora dentro do tradicionalismo.

As representações sociais e culturais são pensadas e vividas pela comunidade local (como os indígenas em suas aldeias, como os quilombolas em seus territórios) como sendo o resultado dos saberes e fazeres praticados pelo próprio grupo cultural. Além disso, sofrem influência dos processos exógenos modernizadores que estimulam a prática da sustentabilidade dos seus territórios tradicionais.

O entendimento sobre a influência da força das representações sobre o cotidiano das comunidades ditas como "tradicionais" passou por longo processo de amadurecimento, já que antes era potencializada por sua plasticidade processual, como afirma Claval (2009, p.17): "De um lado, ela produziu uma imagem conservadora da vida social, mas, de outro, fortaleceu as representações críticas das sociedades modernas concebidas como máquinas". Os pensamentos estavam voltados ao entendimento de que a cultura estava marginalizada e, de certa forma, "controlada" pela democracia, percebida na época como uma modalidade de clonagem da consciência humana tão opressora quanto o das comunidades tradicionais (CLAVAL, 2009).

Os espaços ocupados frequentemente não são configurados por seus atuais ocupantes, antes disso, foram desenhados, segundo Claval (2001), por seus antepassados e pela natureza. Dessa forma, o papel da cultura é preponderante nesse processo de redefinição dos traçados espaciais, mas no sentido mais de reinterpretar esses traçados do que defini-los propriamente, através dos usos do espaço e as relações de afeto que podem a ele ser legados pelas representações da cultura.

Nesse sentido, a situação atual das comunidades indígenas apresenta-se em contextos diferenciados, caracterizando-se ainda pela designação de legado ou herança cultural que lhes confere sentimento de ser, ter e pertencer a seus territórios específicos. A discussão sobre a territorialidade desses grupos tradicionais envolve suas formas de uso do espaço e seus recursos naturais, organização social e econômica, sistemas de valores de uso e simbologia. Isso quando se aloca a questão da 
territorialidade como fator primordial para a construção da própria identidade do grupo, mesmo porque o processo de territorialização de grupos indígenas, ao mobilizar-se em uma coletividade organizada, acaba por unificar uma identidade própria que incidem em sua representação e reestruturação cultural.

Entendendo o conjunto de relações e comportamentos que constituem a complexidade para compreensão do território, vale ressaltar que independente da localização e da questão de territorialidade física e emocional analisada, várias localidades vêm procurando alternativas para promover o planejamento, organização e gestão do território. Um caminho apontado vem sendo o do desenvolvimento com base local e regional sugeridas por Sahlins (1997) como forma de promulgar níveis significativos de melhorias baseados, sobretudo, nas características culturais autóctones. Para o autor,

\begin{abstract}
O desenvolvimento refere-se a um processo - um momento passageiro de "primeiro contato" que pode bem durar mais de cem anos - no qual os impulsos comerciais suscitados por um capitalismo invasivo são revertidos para o fortalecimento das noções indígenas da boa vida (SAHLINS, 1997, p.60).
\end{abstract}

No caso, o fomento da atividade turística com características regionais, autóctones e diferenciadas em territórios culturais deve desvelar que a cultura indígena é capaz de reproduzir um processo direcionado à endogenia local. Repensar o desenvolvimento regional através do turismo, considerando a endogenia existente em um território, significa, portanto, contribuir para o estimulo solidário. Ao buscar ações coletivas que fortaleçam o uso comunitário dos recursos presentes, tendo em vista que a valorização de uma cultura local pode-se propiciar a sua autoafirmação, identidade e melhoria das forças produtivas.

Assim, a atividade turística, tomada como fenômeno inovador, poderia gerar benefícios sociais, culturais, ambientais e econômicos para a comunidade disposta a desenvolvê-la. Os benefícios seriam visíveis, principalmente, no que compete à preservação do seu legado cultural e natural, bem como; no intercâmbio de suas relações primárias e secundárias, oportunizando condições para o desenvolvimento endógeno e participativo do território. Os aspectos relacionados ao turismo serão tratados no próximo capítulo.

\title{
As relações territoriais indígenas como expressão cultural
}

As relações territoriais indígenas são expressões marcantes e complexas ligadas diretamente à identidade cultural. O território incorpora as expressões dos modos de vida tanto do passado, como do presente, contendo, ao mesmo tempo, significados culturais residuais e emergentes. Todo território possui conexões que promovem o movimento e a fluidez e, consequentemente, a (des)territorialização. 
Para Santos (2002, p.9), o território é "[...] lugar em que desembocam todas as ações, todas as paixões, todos os poderes, todas as forças, todas as fraquezas, isto é, onde a história do homem plenamente se realiza a partir das manifestações de sua existência". Incorporando essa concepção territorial à questão da identidade, que, no caso, facilita o entendimento das relações indígenas, entende-se que:

O território não é apenas o conjunto dos sistemas naturais e de sistemas de coisas superpostas. O território tem que ser entendido como o território usado, não o território em si. O território usado é o chão mais a identidade. A identidade é o sentimento de pertencer àquilo que nos pertence. $O$ território é o fundamento do trabalho, o lugar da resistência, das trocas materiais e espirituais e do exercício da vida (SANTOS, 2002, p.10).

Já sobre o conceito de (des)territorialização, Haesbaert (2001, p.175), compreende que:

[...] para os ricos, pode ser confundida com uma multiterritorialidade segura, mergulhada na flexibilidade e em experiências múltiplas de uma mobilidade. [...] Enquanto isto, para os mais pobres, a desterritorialização é uma multi ou no limite, a-territorialidade insegura, onde a mobilidade é compulsória, resultado da total falta de opção, de alternativas, de 'flexibilidade', em 'experiências múltiplas' imprevisíveis em busca da simples sobrevivência física cotidiana.

O conceito de território deriva da conotação "terra", enquanto substrato físico e material. No caso dos indígenas, a (des)territorialização não está totalmente relacionada à exclusão do acesso à terra enquanto meio de produção e subsistência, mas principalmente ao patamar simbólicocultural. Mesmo possuindo o domínio sobre determinado território, podem faltar à sociedade indígena às referências territoriais de suas culturas, que constituem o próprio "imaginário geográfico", condensado simbolicamente em determinadas parcelas de espaços.

Portanto, território para o indígena é ao mesmo tempo um espaço de reprodução física, de subsistência material e um espaço carregado de referências simbólicas para a sua afirmação étnica e para se estabelecerem as diferenças multiculturais no dito "mundo globalizado". É necessário, portanto, combater a (des)territorialização enquanto exclusão sociocultural e espacial de cada povo.

Nessa configuração, existem diversos conflitos quando se trata de questões territoriais, principalmente se comparados às concepções de terra e território entre os indígenas e o Estado, que não são as mesmas. Segundo Faria (2003, p.4): 


\begin{abstract}
A terra indígena, na visão do Estado, é um espaço homogêneo, meio de produção onde estão distribuídos recursos naturais. $\mathrm{Na}$ concepção indígena, terra é um mosaico de recursos naturais, morais e espirituais; seu território, além de conter dimensões cosmológicas, o que não ocorre na concepção de território do Estado. No entanto, território para o Estado é tão somente suporte material onde exerce seu poder e soberania.
\end{abstract}

A diferenciação entre os povos está relacionada também à língua como meio essencial de comunicação humana, sendo componente crucial de qualquer cultura. A influência exata da língua sobre a cultura tem sido estimada, mas nunca estabelecida claramente. Seja como for, a língua, por sua vez, é fortemente afetada por outros aspectos culturais. Quaisquer que possam ser estas inter-relações, a linguagem de uma comunidade é uma de suas características distintivas. A cultura pode certamente abranger ou sobrepor diversos grupos linguísticos diferentes, desde que seja mantido algum tipo de equivalência entre os sistemas simbólicos coexistentes.

Compreendendo os mecanismos de diferenciação, de troca e padronização cultural, destacam-se dois fatos principais na história da cultura: ideias e técnicas tendem a se difundir e a herança cultural dos povos tende a aumentar cumulativamente. Tanto por evolução interna quanto por propagação, a cultura cresce e se dispersa. Quando se fala de "estágios", portanto, não significa que um complexo substitua e elimine outro, mas, exatamente, que aos velhos são acrescentados novos complexos e características culturais, que passam a coexistir. Eventualmente, podem surgir novos padrões, mas eles mantêm os mais velhos (ROSENDAHL; CORREAA, 2003).

Sob este aspecto, é admissível afirmar que o próprio ato de produção altera não somente as condições objetivas, como por exemplo, transformando aldeias em cidade. Surgem também novas possibilidades de transformação para os territórios de modo que as relações possam, por conseguinte, conviver em situação paradigmática, conforme estabelecido entre os novos e antigos padrões para o desenvolvimento do território. Um dos aspectos marcantes das transformações nos territórios indígenas está se projetando para abertura de novas oportunidades, inclusive de negócios, como as relacionadas ao turismo indígena.

\title{
A cultura indígena como produto turístico
}

Como observado na discussão teórica já fomentada anteriormente, a cultura e a tradição vêm ganhando cada vez mais notoriedade como potencial de desenvolvimento. Dentro dessa perspectiva de tradicionalização, o turismo surge como forma de contribuir para a sustentabilidade, sensibilização e educação, mas também, podendo aumentar os conflitos de reajuste do imaginário às diferentes interpretações envolvidas. 
É impossível falar de cultura sem considerá-la como uma das mais importantes motivações das viagens turísticas. Entretanto, o desejo de conhecer a cultura regional nem sempre vem acompanhado do devido respeito, da devida consciência de valor e do legítimo interesse por parte dos visitantes. Os impactos provocados pelo turismo na cultura merecem especial tratamento quando os objetivos são contrários ou conflitantes ou as diferentes culturas se repelem, provocando difícil aceitação ao ateio do turismo.

Relacionando essa problemática ao turismo indígena, as atrações desenvolvidas por eles no que se referem às danças, as indumentárias, aos rituais, aos hábitos e costumes são valores subjetivos de caráter espiritual e nem sempre todas as manifestações podem ser apresentadas ao público espectador. Portanto, as interferências do visitante sobre essas características podem gerar constrangimento e falta de respeito à própria cultura indígena. Isso acontece principalmente pela falta de conhecimento do visitante sobre a cultura do povo visitado, já que não deve prevalecer o que ele deseja ver, e sim o que é possível a partir da determinação da comunidade local (JESUS, 2012).

Diferentes fatores concorrem com intensidades e ritmos temporais e espacialmente diferenciados para a produção do espaço turístico. Mais ainda, esses fatores já não são apenas de ordem local, mas, também, em grande parte são deflagrados em espaços muitos distantes daqueles sobre os quais exercem alguma influência.

Para Coriolano (2001, p. 218),

[...] O espaço turístico é, antes de mais nada, uma imagem feita pelas representações de quem pretende viajar. São imagens complexas, constituídas de sonhos e vocações, com a ajuda de audiovisuais como cartazes, guias, prospectos, folhetos, livros, filmes, cassetes e internet. Todas cheias de ambivalência, contradições e do duplo movimento entre imaginário e real ou entre real e imaginário.

Diante dessa constatação, acrescenta-se que toda análise que se pretenda fazer sobre a complexidade turística que é encenada consiste na participação do turismo na produção do espaço geográfico, ou seja, na criação de territórios turísticos artificiais e/ou naturais, considerando o conjunto de relações nas suas dimensões global e local.

Dois fatores principais condicionam a determinação de espaços para o uso turístico: sua valorização cultural estimulada pela prática social do turismo e a divisão social territorial do trabalho. Como a valorização dos espaços pelo turismo é dada em função de valores culturais e ela é própria de grupos sociais, além de estes valores serem mutáveis no tempo, os territórios atuais não correspondem, necessariamente, aos destinos turísticos futuros. 
Destaca-se que o turismo tem como objetivo a experiência implicada na apreensão subjetiva das relações sociais e culturais concretas na arena a ser visitado, com fluxo comunicativo presente numa situação histórica marcada pelo contato de diversos segmentos sociais e gerado a partir da criação de um polo turístico. No entanto, como na maioria das vezes é tratado apenas pelo viés econômico, esquece-se de questões sociais, culturais e ambientais inseridas no planejamento, surgindo como resultado interferência inconsequente, provocando a destruição, o desarranjo e até mesmo o conflito (JESUS, 2012).

O visitante gosta de entrar num mundo diferente do seu habitual e de experimentar coisas, produtos e lugares desconhecidos, até mesmo atitudes diferentes em relação à sociedade e ao meio ambiente. Todavia, os efeitos gerados pela atividade turística contribuem para um mercado promissor sobre a "comercialização" de culturas, entre elas a indígena. Tal produção gerada pelo turismo amplia a possibilidade de uma alternativa econômica, criada e desenvolvida por povos indígenas tanto no Brasil como exterior e promove transformações de territórios indígenas em territórios turísticos.

Conflituosamente, pouco se lê sobre os impactos advindos dessa disseminação da prática turística envolvendo comunidades indígenas, inclusive das próprias definições que abarcam essa modalidade que, muitas vezes quando encontradas, são relacionadas ao turismo cultural; turismo étnico ou etnoturismo; turismo nativo; turismo comunitário ou de base comunitária; ecoturismo; ecoturismo indígena; entre outros, a fim de buscar conceituação mais próxima da realidade do que se objetiva com o segmento turismo indígena.

Nesse sentido, recorrendo aos principais autores e principalmente às organizações que apresentam suas definições para contextualizar a prática do turismo em ambientes culturais. Para o Ministério do Turismo do Brasil (MTur), o turismo cultural "[...] compreende as atividades turísticas relacionadas à vivência do conjunto de elementos significativos do patrimônio histórico e cultural e dos eventos culturais, valorizando e promovendo os bens materiais e imateriais da cultura" (MTur, 2011, p.1).

A referência acima citada apresenta parte do que está sendo proposto na busca de definição mais próxima do termo turismo indígena, uma vez que em se tratando exclusivamente do turismo cultural, sua conotação relaciona-se principalmente ao patrimônio material e imaterial. É evidente que na complexidade das atividades esses elementos são elementares, porém, não exclusivos na prática da atividade em si, já que as atividades voltadas à natureza são desencadeadores de especificidades marcantes das simbologias e territorialidade indígenas.

Recorrendo ao entendimento do que vem ser o turismo étnico, também denominado etnoturismo, o MTur (2011, p.1) define que: "consiste na visitação de locais onde um modo de vida distinto do seu possa ser observado e explorado. O objetivo é ver de perto os pequenos grupos sociais em seu ambiente natural, com suas particularidades e tradições e, assim, aprender com elas".

Os elementos tratados acima proporcionam proximidade do que se deseja aplicar com as particularidades advindas da experiência provocada 
no turismo indígena. Entretanto, sua definição é complexa e abarca grupos étnicos diferenciados como também os quilombolas, faxinais, imigrantes, entre outros encontrados no território brasileiro. Esse tipo de modalidade surgiu no cenário turístico mundial como opção de lazer e entretenimento para pessoas que têm interesse em conhecer povos, culturas e tradições diferentes. Para definição mais próxima do que se pretende com turismo indígena nesse tópico, serão emprestados diversos elementos do turismo étnico para sua composição.

Já o turismo comunitário ou de base comunitária tem por objetivo, segundo o Ministério do Turismo visa "[...] estimular o desenvolvimento da atividade e a geração de emprego e de renda no país. Essa iniciativa permite que as comunidades locais assumam a gestão e a oferta de produtos e serviços turísticos" (MTur, 2011, p.6).

Complementando mais ainda o conceito de turismo comunitário, Sampaio (2005), ao longo de seus estudos voltados às ações de base comunitária, evidencia o segmento como ação de comunicação social. Tal ação favorece as experiências de planejamento para o desenvolvimento de base local, no qual os habitantes de determinada comunidade se tornam os principais atores da cadeia produtiva, bem como, na revitalização e conservação de seus modos de vida, os quais podem ser vivenciados através da atividade turística. Assim, as comunidades tradicionais que vivem em espaços rurais podem conservar modos de vida próprios, manifestados em suas atividades produtivas agrícolas e através de seu artesanato local.

Seus preceitos encaixam-se com os valores tratados no turismo indígena, entretanto, quando se considera que a cultura indígena é dinâmica e diversificada, e que os povos indígenas estão localizados tanto em espaços rurais, quanto dentro de perímetros urbanos, torna-se necessária uma adequação epistemológica. Assim, é importante o ajuste do termo a dinâmica social que se intenta na terminologia utilizada.

Entre as definições e práticas que vêm sendo abordadas para compreender alguns dos elementos que arranja o turismo indígena é o ecoturismo. Muitas comunidades indígenas vêm recorrendo as técnicas fomentadas pelo ecoturismo para composição e comercialização de seus produtos turísticos. Assim, o ecoturismo pode ser definido segundo o Ministério do Turismo como:

[...] segmento da atividade turística que utiliza, de forma sustentável, o patrimônio natural e cultural, incentiva sua conservação e busca a formação de uma consciência ambientalista por meio da interpretação do ambiente, promovendo o bem-estar das populações (MTur, 2011, p.2).

Nesse sentido, o conceito apoia-se sobre o tripé: interpretação, conservação e sustentabilidade. Considerando os aspectos abordados acima, o Ministério do Meio Ambiente (MMA) publicou no ano de 1997, documento denominado Manual Indígena de Ecoturismo para disseminar, 
por meio de uma linguagem acessível, às vantagens que o ecoturismo pode proporcionar as comunidades indígenas brasileiras. Na introdução, através da pergunta Por que fazer ecoturismo na terra dos índios? o Manual responde: "Porque é um jeito dos índios ganharem um pouco de dinheiro. A borracha, o artesanato, a farinha e outros produtos que o índio vende, não dão prá comprar todas as coisas de que ele precisa" (MMA, 1997, p.28).

Outra pergunta (MMA, 1997, p.30) Será que é bom ou ruim fazer ecoturismo em terras indígenas? Para essa pergunta existem duas respostas, sendo que a primeira apresenta algumas vantagens: "mostrar a riqueza da cultura indígena; ajudar a proteger e conservar a natureza; reafirmar a importância e a beleza das terras indígenas; ganhar dinheiro". A segunda apresenta as seguintes desvantagens: "risco de trazer doenças para a aldeia; atrapalhar as atividades tradicionais; risco de introduzir vícios e hábitos que fazem mal; desrespeito a rituais e locais sagrados" (MMA, 1997, p.31).

Em linhas gerais, o Manual traz informações que contribuem para a disseminação do que vem a ser a atividade turística nos territórios indígenas. Fica evidente que a tradição cultural deve prevalecer sobre os interesses do ecoturismo, ou seja, respeitar e valorizar a cultura local. A comunidade deve participar de todo o processo do turismo em suas terras, inclusive na gestão do ecoturismo por meio do associativismo, gerando renda e qualidade de vida. Além disso, elucida que a atividade deve ser uma atividade complementar e de apoio a conservação das práticas tradicionais e dos projetos desenvolvidos pela comunidade indígena.

A conceituação do termo numa visão acadêmica que é adotada por diversas organizações internacionais - Organização Mundial do Turismo (OMT), World Tourism Association (WTO), Programa das Nações Unidas para o Meio Ambiente (PNUMA), Sociedade Internacional de Ecoturismo The International Ecoturismo Society (TIES) advêm do mexicano Hector Ceballos-Lascurain que em 1983 definiu o ecoturismo como "encontro do Homem com a Natureza em seu estado selvagem" (CEBALLOSLASCURÁIN, 1995, p.19). Com o passar do tempo, o mesmo autor ampliou a definição como "modalidade turística que tem como motivação principal viajar para áreas naturais, pouco modificadas e livres de contaminação, com o objetivo específico de estudar, admirar e desfrutar ativamente de suas paisagens, plantas e animais existentes nessas áreas" (IDEM, 1995, p.19).

Observando os conceitos atribuídos ao ecoturismo relacionados ao que se deseja definir o turismo em território indígena, ainda não contempla por completo os aspectos que a atividade promove. As definições apontam, no primeiro caso, com o Mtur, que o turista ou visitante atua como observador e, tem de certa forma, posição passiva em relação à natureza e de pouca responsabilidade. No segundo caso, com o Manual elaborado pelo MMA, apesar de as informações serem importantes, emprestou do conceito tratado no ecoturismo sem as devidas adaptações e, além disso, não atingiu muitas comunidades indígenas na época da publicação e, após esse período não houve outra ação dirigida. No terceiro caso, Ceballos-Lacurian (1995) defende que a atividade requer diferentes atores sociais no processo provocado pelo turismo, além do exercício de suas responsabilidades sociais, culturais e ecológicas. Portanto, depende da integração do turista, 
de sua preocupação e seu compromisso com o meio ambiente, visando reduzir as interferências negativas e maximizar os pontos positivos em busca do desenvolvimento sustentável.

Aproximando o campo teórico para a realidade prática, várias comunidades indígenas do Brasil como os Pataxó na Bahia, os Caiapó no sul do Pará, os indígenas do Xingu do Mato Grosso, os Marajoaras do Pará, como também de outros países como os Māori (Nova Zelândia), Mapuche (Chile), Nevería (México), Wichí (Argentina), Kuna (Panamá), Maracaíbo (Venezuela), entre outros, vêm desenvolvendo a atividade turística baseada nas técnicas advindas do ecoturismo. Deste modo, o termo está diretamente associado ao turismo sustentável, ou seja, relaciona as necessidades dos turistas e das regiões receptoras, protegendo e fortalecendo oportunidades para as futuras gerações. Considera ainda a gestão dos recursos econômicos e sociais além das necessidades estéticas, conservando a integridade cultural, os processos ecológicos essenciais, a biodiversidade e os sistemas de suporte à vida.

Recorrendo-se a uma das poucas referências encontradas, especificamente sobre o turismo indígena, baseado na tese defendida no Programa de Pós Graduação em Geografia da Universidade de São Paulo (2008) intitulada Ecoturismo Indígena Território, Sustentabilidade e Multiculturalismo: princípios para a autonomia, de Ivani Ferreira de Faria (2008, p.46-47), que define o segmento como:

O turismo indígena, como o nome sugere, é o turismo desenvolvido nos limites das terras indígenas ou fora deles com base na identidade cultural e no controle da gestão pelo povo-comunidade indígena envolvida.

[...] O fato de povos e comunidades indígenas desenvolverem atividade turísticas fora dos limites de suas terras não desqualifica o tipo de turismo e nem os valores culturais e sua identidade, pois a cultura e a identidade permanecem com eles. Por ser realizado nos núcleos populacionais, meio urbano ou rural, de modo que não afete negativamente a cultura dos povos e comunidades envolvidas por meio de várias estratégias que deverão ser pensadas e planejadas junto com a comunidade, técnicos, entidades indígenas, indigenistas e ambientalistas.

Com essa definição, fica evidente a motivação das pessoas em se deslocarem a atrativos turísticos culturais, como por exemplo, dando enfoque à cultura indígena. $\mathrm{O}$ estar presente em uma aldeia indígena ou até mesmo transformada exclusivamente para a comercialização do artesanato, das danças, do modo de vida indígena, possibilita a experiência turística, seja ela satisfatória ou não, dependendo do olhar de cada visitante. Agregado ao contexto, a autora ainda elucida a importância do ecoturismo nos territórios indígenas, classificando-o em uma nova segmentação turística. Para Faria (2008, p.47) o ecoturismo indígena é: 
[...] o ecoturismo promovido dentro dos limites das terras indígenas através do planejamento - gestão participativa e comunitária, respeitando os valores sociais, culturais e ambientais dos diferentes povos envolvidos em que a comunidade é a principal beneficiada.

A autora defende ainda, em seus estudos, que o ecoturismo indígena é a modalidade turística que melhor atende as necessidades das comunidades indígenas levando em conta a possibilidade que organização e gestão participativa entre os atores envolvidos na composição do produto que respeite a identidade, territorialidade e alteridade cultural, além de estabelecer critérios para seu desenvolvimento e comercialização. Assim posto, para Faria (2008) tanto o turismo indígena como o ecoturismo indígena convergem na essência e aos objetivos de promoverem à cultural e ao melhoramento da qualidade de vida das comunidades envolvidas. $\mathrm{O}$ fato que diferencia dos demais tipos de segmento turístico, além das formas específicas de planejamento, são os limites que cada uma das modalidades abrange, ou seja, a primeira restringe-se ao contorno dos territórios e fora deles, já a segunda, o ecoturismo indígena, está compreendida dentro dos territórios demarcados ou tradicionalmente ocupados.

O turismo envolvendo indígenas, tanto dentro como fora de seus territórios ocupados, é tratado com diversidade de opiniões, principalmente no que se relaciona à sua autenticidade. Os indígenas, que são os atores da representação cultural e na luta pela sobrevivência, sofrem, em muitos casos, com as relações mercadológicas para produção e comercialização dos objetos e artefatos culturais. Os empresários do setor turístico, que assumem a responsabilidade pela venda do artesanato, por exemplo, muitas vezes canalizam o lucro para si mesmo, com pouca participação dos indígenas. O poder público que fomenta a atividade pelo fato da geração de divisas e imposto para o local, critica a atividade pelo fato de destinar permanentemente recursos financeiros e logísticos para a manutenção dos serviços prestados. Os turistas, transformados em espectadores da encenação cultural apresentada por parte dos indígenas, frustram-se em alguns casos, pela falta de tradição "primitiva". Até mesmo os cientistas tratam do assunto com restrições, principalmente em função dos impactos sociais, culturais e econômicos gerados por tal atividade (JESUS, 2012).

Grünewald (2001) defende a ideia de que a partir do momento que as pessoas pensam que existem experiências turísticas inautênticas, elas não mais conseguirão perceber a dinâmica de uma sociedade em termos gerativos. Ignorarão que, ao defrontar com a experiência turística, as comunidades e suas culturas locais podem se transformar na gênese de novos padrões e permanecer autênticas, mesmo por meio de mudanças sociais e culturais.

A questão da autenticidade como perspectiva turística existe de fato, mas não é instrumental nem mesmo para compreender a movimentação dos turistas para os lugares de visitação. Segundo Grünewald (2001, p.36) "Mesmo na quebra das expectativas quanto à autenticidade das construções locais, isso não tira a autenticidade de sua cultura, uma vez 
que ela foi gerada em um contexto que, embora não considerado pelos turistas, é socialmente legítimo".

As contradições acerca da atividade turística como fator autêntico ou inautêntico estão principalmente relacionadas à fragmentação étnica, cultural e homogeneização das tendências constitutivas da realidade global. Tem-se, assim, que o modo de produção capitalista permanece tão intacto e sistematicamente coeso, que contribui rapidamente para aceleração e massificação dos destinos turísticos.

O turismo requer cuidados em seu planejamento para que seus impactos sejam minimizados. Para tanto, é necessário observar alguns critérios, como os efeitos econômicos do turismo sobre a indústria de artes e ofícios merecem menção especial, já que o turismo tem servido para regenerar indústrias tradicionais ao prover mercado ampliado para produtos nativos. A interação entre o mercado mundial e a identidade cultural, entre o processo local e global, entre o consumo e as estratégias culturais; faz parte da tentativa de descobertas da lógica envolvida nesses problemas aparentes.

\section{Considerações finais}

Buscou-se até agora, abordagens teóricas e conceituais que pudessem subsidiar a apreensão da realidade sofre enfoque ligados ao território, territorialidade, tradição, cultura, entre outros elementos que são base analítica para a construção do campo conceitual que abarca o turismo indígena.

A objetificação da cultura prende-se à necessidade de encontrar coisas a que a identidade dos grupos possam se fixar. Na visão de Silvano (2002, p.11): "Dito de outro modo, coisas que permitam o duplo movimento - de identificação consigo próprio e de diferenciação face aos outros - que o jogo identitário sempre implica".

Assim, o turismo surge como imenso jogo cultural em que as populações mundiais se encontram para se reconhecerem como detentoras de patrimônios culturais diferentes. A patrimonialização passa, inevitavelmente, pela presença, mesmo que imaginária, de interlocutores exógenos à origem dos objetos tornados patrimônios, contribuindo para a validação cultural, já que a visão externa do "outro" serve de parâmetro para transformar as próprias práticas culturais em algo extraordinário.

A lógica de patrimonialização dos recursos culturais e naturais existentes corresponde essencialmente às dinâmicas de representatividade simbólica individual e coletiva. Nesse sentido, são construídas no interior dos conflitos culturais que envolvem os diferentes grupos que constituem uma sociedade. $O$ papel das localidades em que se projetam perspectivas de valorização cultural, até mesmo com o planejamento inadequado, provocando a descaracterização cultural, está muitas vezes, relacionado às formas que se criam, ou não, o sentimento de pertença. Sentimento este que liga o poder simbólico e emocional, apesar da diversidade e do espaço envolvido sobre a população alvo, ou seja, no caso em questão, sobre as comunidades indígenas. 
No espaço apropriado pelo turismo é preciso pensar além das suas funções econômicas, considerar as questões sociais e culturais diversas. A necessidade de reforço desse sentimento terá de ser produzida em articulação com a multiplicidade de processos de identificação territorial de escala mais reduzida.

Após a análise conceitual abordada anteriormente, que buscou entre diferentes conceitos, as terminologias e elementos que auxiliam a constituição de uma definição mais precisa sobre o turismo indígena, é que segundo Jesus (2012, p.78):

O turismo indígena pode ser compreendido como um segmento da atividade turística que é desenvolvido dentro ou fora dos territórios tradicionais, segmento este que fomenta ações de base comunitária abarcando em sua essência a conservação e sustentabilidade sociocultural e ambiental, bem como a revitalização de modos de vida tradicional coesos com a realidade de vida atual, além da geração de renda para a própria comunidade envolvida. Para sua composição a comunidade indígena decidirá as ações a serem desenvolvidas e posteriormente articuladas com os agentes de fomento do turismo.

Considerando a dinâmica evolutiva na tradição dos povos, a prática do turismo indígena não se restringe a cultura materializada e estanque no tempo, uma vez que os povos indígenas acompanham as tendências mundiais de desenvolvimento, não desmerecendo seus valores tradicionais de identidade e alteridade étnica. Não se trata, portanto, de questionar sua autenticidade, pois a própria experiência turística promove de fato a prova de intercâmbio intercultural entre o indígena e o visitante do atrativo. Além disso, limitar a abrangência de desenvolvimento da atividade (se acontece dentro ou fora do território indígena) para definir uma modalidade da outra não contribui para o próprio conceito de território e territorialidade (como defendido por Santos e Haesbaert), que os compreende como um sistema em que os atores usufrui cotidianamente do território deixando suas marcas culturais independente de sua autoctonia. Ou seja, tanto faz o indígena estar dentro ou fora do território tradicional ele levará consigo sua manifestação de identidade e alteridade cultural inclusive na produção turística em que estiver inserido (JESUS, 2012).

Como se percebe, a consolidação do ambiente cultural interétnico dependerá do equilíbrio resultante do jogo instável e infinitamente manipulável, entre a afirmação das semelhanças e a aceitação das diferenças entre os indivíduos que convivem dentro do mesmo ambiente social e que constituem uma única sociedade, seja ela composta por índios ou não indígenas. 


\section{Referências bibliográficas}

BRASIL. Ministério do Turismo (Mtur). Turismo cultural: orientações básicas. Disponível em: http://institucional.turismo.gov.br/arquivos open/diretrizes manuais/TurismoCult ural.pdf. Acesso em 01.03.2011, 15h.

BRASIL. Ministério do Meio Ambiente. Manual Indígena de Ecoturismo. Programa-Piloto Ecoturismo em Terras Indígenas. MMA: FUNAI: OEA: SUDAM: PRODEAM, Brasília, 1997.

CEBALLOS-LASCURAIN, H. O ecoturismo como um fenômeno mundial. In: LINDBERG; K.; HAWKINS, D. (ed.). Ecoturismo: um guia de planejamento e gestão. Tradução de Leila Cristina de M. Darin, São Paulo: Senac, 1995.

CLAVAL, P. A geografia cultural. 2. ed. Florianópolis: UFSC, 2001.

CLAVAL, P. Globalização, migrações, inclusão e exclusão: algumas reflexões. In: ALMEIDA, M.G.; CRUZ, B.N. Território e Cultura: inclusão e exclusão nas dinâmicas socioespaciais. Goiânia: UFG, 2009, p.10 - 25.

CORIOLANO, L. N. M.T. O real e o imaginário nos espaços turísticos. In: ROSENDAHL, Z.; CORRÊA, R. L. (orgs). Paisagem, imaginário e espaço. Rio de Janeiro: EdUERJ, 2001.

FARIA, I. F. Território e territorialidades: indígenas do Alto Rio Negro. Manaus: Editora da Universidade Federal do Amazonas, 2003.

FARIA, I. F. Ecoturismo Indígena Território, Sustentabilidade e Multiculturalismo: princípios para a autonomia. São Paulo, 204 p. Tese (Doutorado em Geografia Física) - Programa de Pós Graduação em Geografia Física, Universidade de São Paulo (USP), São Paulo, 2008.

GRÜNEWALD, R.A. Turismo e o "resgate" da cultura Pataxó. In: BANDUCCI Jr, A.; BARRETO, M. (Org.). Turismo e Identidade Local. Uma visão antropológica. São Paulo: Papirus, 2001.

HAESBAERT, R. Da desterritorialização à multiterritorialização. Anais do IX Encontro Nacional da ANPUR. vol. III. Rio de Janeiro: ANPUR, 2001.

JESUS, D.L. A (re)tradicionalização dos territórios indígenas pelo turismo:um estudo comparativo entre os Kadiwéu (Mato Grosso do Sul, BR) e Maori (Ilha Norte, NZ). Curitiba, 2012. 264f. Tese (doutorado) Universidade Federal do Paraná, Setor de Ciências da Terra, Curso de Pós Graduação em Geografia.

LÖWEN SAHR, C. L. Os "mundos faxinalenses" da floresta com araucária do Paraná: racionalidades duais em comunidades tradicionais. Ponta Grossa: Terr@Plural, 2 (2): 213-226 , jul./dez., 2008.

ROSENDAHL, Z. e CORRÊA, R. L.(orgs). Introdução a geografia cultural. Rio de Janeiro: Bertrand, Brasil, 2003.

SAHLINS, M. O "pessimismo sentimental" e a experiência etnográfica: por que a cultura não é um "objeto" em via de extinção (Parte I). Mana, abr. 1997, vol.3, no.1, p.41-73. ISSN 0104-9313.

SAMPAIO, C.A.C. Turismo como fenômeno humano: princípios para se pensar a socioeconomia e sua prática sob a denominação turismo comunitário. Santa Cruz do Sul: EDUNISC, 2005. 
SANTOS, M. O dinheiro e o território. In: SANTOS, M. (org). Território territórios. Niterói: Programa de Pós-Graduação em Geografia: UFF: AGB, 2002.

SILVANO, F. Cartografar um passado para uma identidade metropolitana. In: Património Metropolitano, Inventário Geo-referenciado do Património da Área Metropolitana de Lisboa: Universidade de Lisboa: Sistema Metropolitano de Informação Geográfica, Lisboa, 2002, p. 208-225.

Djanires Lageano Neto de Jesus: Universidade Estadual de Mato Grosso do Sul, Campo Grande, MS, Brasil.

E-mail: netoms@uems.br

Link para o currículo Lattes: http://lattes.cnpq.br/0080447988753959

Data de submissão: 25 de maio de 2012

Data de recebimento de correções: 03 de abril de 2014

Data do aceite: 03 de abril de 2014

Avaliado anonimamente 